\title{
THE MEASUREMENTS POSSIBILITIES OF ACOUSTIC DAMPING IN COMPOSITE MATERIALS
}

\section{E. Pileckas}

\author{
Antanas Gustaitis Aviation Institute of Vilnius Gediminas Technical University, Department of Avionics. \\ E-mail: jugen@delfi.lt
}

Received 1210 2004, accepted 13122004

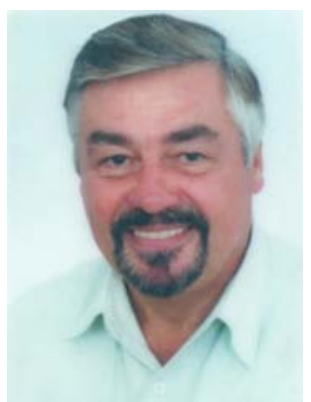

\author{
Eugenijus PILECKAS, Prof Dr Habil \\ Date and place of birth: 1941, Trakai, Lithuania. \\ Education: 1965- Kaunas Polytechnics. 1974 - PhD, 1985 - D Sc, 1987- Prof. \\ Experience: Head of Department of Ultrasonic Medicine Technology in Radio Measurements Scientific Researches \\ Institute 1965-1986. Head of Department of Electronics in Kaunas Technology University 1986-1991. Director \\ General of "Elita" - Institute of Scientific Researches in Electronics 1991-1998. Professor in Antanas Gustaitis \\ Aviation Institute of Vilnius Gediminas Technical University, Department of Avionics since 1998. \\ Awards: laureate of two state science prizes. \\ Publications: Author of two monographs, three books, 80 inventions, several hundred articles and conference papers.
}

Abstract. With the wider use of composite materials in aviation, the observation of their quality during exploitation is becoming more topical. We are of the opinion that acoustic technologies of all in one control offer us promising possibilities to observe and research the characteristics and parameters of composite materials. The purpose of this paper is to discuss some accepted ways of tuning the damping of the acoustic signals in non-homogeneous environments for research of composite materials.

Key words: Composite materials, ultrasonic waves, piezoelectric converter, damping parameters, ultrasonic pulse, spectrum, measurements.

\section{Introduction}

While ultrasonic waves are wafting in materials, their intensity declines gradually because of absorption and scatter. Damping of the wave, which depends on the frequency of the ultrasound, is defined by the coefficient of acoustic damping $-\alpha$. This coefficient in turn depends on the characteristics of materials and can be useful in identifying the separate states of materials.

Assuming that, the damping coefficient in study material $\alpha(f)$ is directly proportional to the frequency of ultrasound:

$$
\alpha(f)=\beta f,
$$

Establishment of the bent quiescent of acoustic damping coefficient can change this measurement $\beta$. There are several known methods to establish the bent quiescent of acoustic damping coefficient $\beta$ while researching material in the echo-impulse way. This way of researching material is then ultrasonic wave impulses are actuated by piezoelectric converter. And these impulses are running to the same direction.

Impulses reflected from the structural elements of the specimen or its external elements are retraced to piezoelectric converter, where those signals are changed into an electric signal. After that, this electric signal is analyzed in frequentative or time ranges. The most popular are frequentative (spectral-difference and spectral-shift acoustic damping measurement) methods

and time (zero-crossing and adaptable discretion) methods.

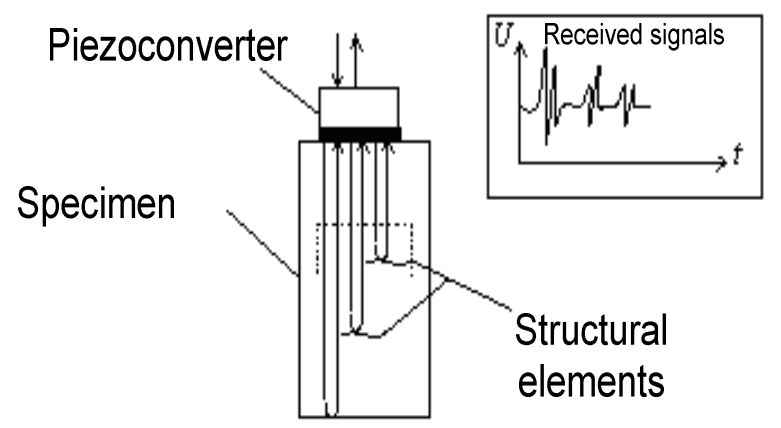

Fig 1. Echo-impulse method

Those methods are validated by the assumption that acoustic energy is wafting across the specimen in the form of a longitudinal ultrasonic wave. The key feature of those waves is damping:

$$
I_{F}=I_{N} e^{-2 \alpha d}
$$

Where

$I_{N}, I_{F}$ is the intensity of flat waves (Figure 2),

$d$ is the thickness of the layer,

$\alpha$ is the comparative damping coefficient in decibels. 

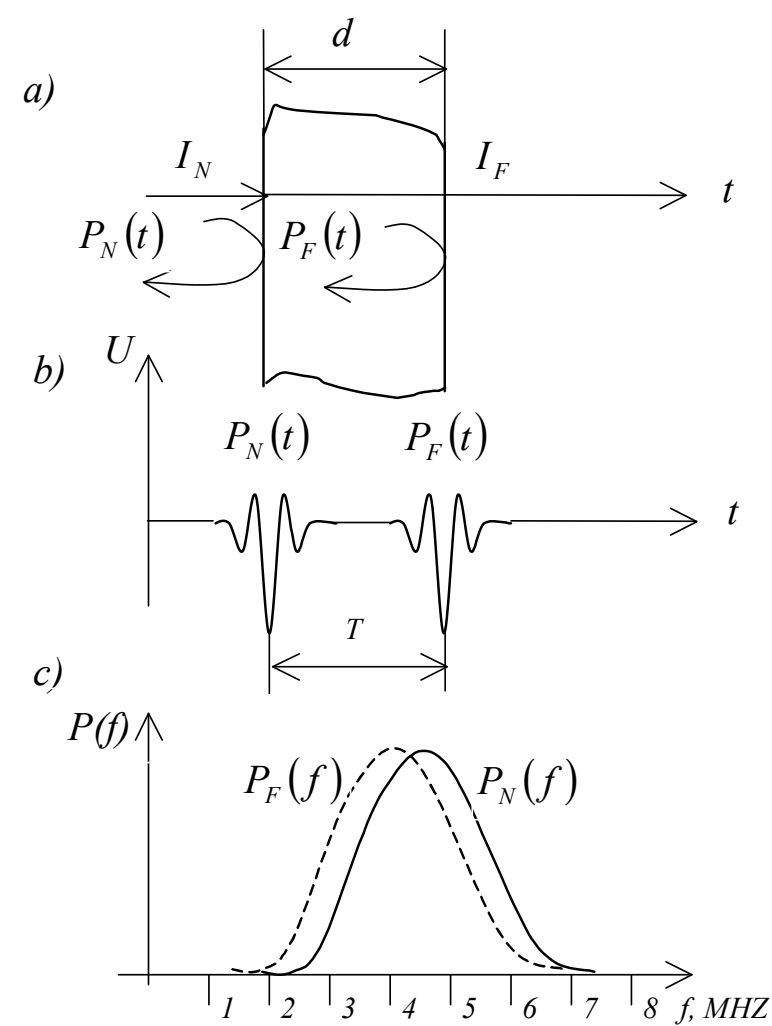

Fig 2. For better understanding of spectral-shift method: a - elementary indiscrete layer of material, which is under the sway of ultrasonic radiation,

$\mathrm{b}$ - reflected ultrasonic impulses (from frontal and terminal boundary of layer),

$\mathrm{c}$ - the density of spectral power of ultrasonic impulses

\section{Spectral-difference method}

This method allows us to establish $\beta$ according to the alteration of difference of the power spectrum logarithms of reflected ultrasonic impulses. The power transfer characteristic of ultrasonic impulses at the layer surface of the specimen is:

$$
|H(f)|^{2}=\frac{P_{F}(f)}{P_{N}(f)},
$$

Where

$$
P_{N}(f) \text { - spectral power density of ultrasonic }
$$
impulse (reflected from frontal layer boundary),

$P_{F}(f)$ - spectral power density of ultrasonic impulse (reflected from terminal layer boundary).

Those two ultrasonic impulses are separated in time: $T=2 d / c$, where $c$ - the speed of sound.

The comparative damping coefficient is directly connected with this transient characteristic:

$$
\left|H(f)^{2}\right|=10^{[-\alpha(f)(2 d)]] / 10}=10^{-0,2 \beta f d}
$$

Or equivalent:

$$
\alpha(f)=\frac{-10 \lg |H(f)|^{2}}{2 d}
$$

Where: $2 d$ - pathway length in layer.

Then function (3) is expressed into logarithmic units (decibels), the parameter $\beta$ :

$$
\beta=\frac{10 \lg P_{N}(f)-10 \lg P_{F}(f)}{2 d f}
$$

The advantage of this method is that the utilization of this method does not depend on the shape of signal spectrum.

\section{Spectral-shift method}

This method allows us to establish $\beta$ according to the spectrum shift to the low frequency area of reflected ultrasonic impulse.

This method requires using ultrasonic impulses with Gauss shape envelope and harmonic carrier frequency.

$$
P_{N}(f)=C_{N} e^{-\left(f-f_{N}\right)^{2} / B^{2}},
$$

Where: $C_{N}-$ constant; $B-$ the width of the ultrasonic impulse spectrum; $f_{N}-$ the central spectrum frequency.

In paper [3], it was shown that spectrum $P_{F}(f)$ is exactly the same Gauss shape as spectrum $P_{N}(f)$. Only carrier frequency $f_{F}$ is variable.

$$
f_{F}=f_{N}-2 \beta d B^{2},
$$

It means that $P_{F}(f)$ shifts to the low frequency area.

Thus, we can calculate the values of $\beta$ according to the shift of carrier frequency:

$$
\beta=\frac{f_{N}-f_{F}}{2 d B^{2}} .
$$

It was proven that the accuracies of both acousticdamping methods are equal, although earlier it was reputed that the spectral-shift method was more exact [5]. It was so because of extra a priori information about the Gauss form of the power spectrum.

We must do a lot of calculations to establish the spectrum of ultrasonic impulse. It is the main lack of this method. Therefore the speed of measurements decreases.

\section{Zero-crossing method}

This method allows us to establish the value of $\beta$ according to the zero-crossing density of Gauss shape ultrasonic impulses. The link between zero density $\lambda$, average quadratic frequency $f_{1}$ and central frequency of spectrum $f_{e}$ are used in this method. 


$$
\lambda=2 f_{1}=2\left(f_{e}^{2}+\frac{\sigma^{2}}{2}\right)^{\frac{1}{2}}
$$

$\sigma-$ spectral dispersion.

We can describe the link between zero-crossing density of the ultrasonic impulse and alteration of damping coefficient $\beta$ :

$$
\lambda=2 f_{0}-4 \sigma^{2} \beta d+\frac{\sigma^{2}}{2 f_{0}},
$$

$f_{0}-$ central spectrum frequency, which is equal to carrier frequency of ultrasonic impulse. So

$$
\beta=\frac{\left(\frac{f_{0}}{2 \sigma^{2}}-\frac{\lambda}{4 \sigma}+\frac{1}{8 f_{0}}\right)}{d} .
$$

The zero-crossing method has a great advantage; we do not need to calculate spectral characteristics.

\section{Adaptable discretion method}

According to the adaptable discretion method, the acoustic damping of material is adjusting by using the average adaptable discretion frequency of ultrasonic impulse.

The average quadratic frequency $f_{1}$ :

$$
f_{1}=\frac{f_{d} \varepsilon}{2 \pi K_{\Phi} \sigma_{x}}
$$

Where: $K_{\Phi}-$ is the coefficient which depend on the form of fluxion, $\varepsilon-$ bias of approximation; $\sigma_{x}-$ average quadratic alteration.

Zero density of signal has this form:

$$
\lambda=2 f_{1}=\frac{f_{d} J}{\pi K_{\Phi}}
$$

Where: $J=\varepsilon / \sigma_{x}$ is the reduced altitude.

Next two equations describes the link between the average frequency of the adaptable discretion and $\beta$ :

$$
\begin{aligned}
& f_{d}=\pi K_{\Phi}\left(2 f_{0}-\frac{4 \sigma^{2} \beta d+\sigma^{2}}{2 f_{0}}\right) J \\
& \beta=\frac{\frac{f_{0}}{2 \sigma^{2}}-f_{d} J}{\left(4 \pi K_{\Phi} \sigma^{2}+\frac{1}{8} f_{0}\right) d}
\end{aligned}
$$

The value of $f_{d}$ is adjusted in real time. Because of it, the adaptable discretion method has all the advantages of the zero-crossing method, and the sensibility of the damping coefficient measurements is far better. This means that sensibility increase $\frac{K_{\Phi}}{J}$ times.

But enlarging sensibility by decreasing attitude $J$ is limited by the speed of adaptable discretion.

Therefore, this method requires complex technologies while zero-crossing method can be realized in much more simple way.

\section{Double frequency method}

The methods of acoustic damping measurements that we analyzed above are based on the dependence of the direct damping coefficient on frequency. Yet from the results of experiments, we can conclude that the dependence of the functional damping coefficient can vary from direct to quadratic. This variation depends on type and condition of material.

$$
\alpha(f)=\alpha_{0} f^{m}
$$

Where: $1 \leq m \leq 2, \alpha_{0}-$ damping quiescent.

Besides, to estimate the damping coefficient, it is possible to use the simpler double frequency method [10]. The double frequency method is legitimated by amplitude measurements of two reflected ultrasonic impulses generated on two different frequencies. Within the given frequentative dependence, the damping quiescent can be expressed:

$$
\alpha_{0}=\frac{A_{21}-\left[A_{22}+A_{22}\left(A_{11}-A_{12}\right)\right]}{2 d\left(f_{1}^{m}-f_{2}^{m}\right)},
$$

Where: $\quad A_{11}, A_{12}, A_{21}, A_{22}-$ amplitudes of ultrasonic impulses reflected from frontal and terminal surfaces of specimen. Those amplitudes are obtainable then two ultrasonic probe frequencies $f_{1}$ and $f_{2}$ are $f_{1} \triangleleft f_{2} ; m=1 \div 1,2 ; d-$ the thickness of layer. Yet this method requires using probe frequencies. The band of relative frequentative spectrum must be less than 0,1 .

\section{Modeling confines}

All above discussed measurements methods of the acoustic damping are under the influence of the spectrum width, central frequency, mirror image, scatters in the materials. Some of these factors depend on the technique of experiment; others depend on the character of the material. It is therefore very important to choose either correct methodic for acoustic damping measurements or correct technical means.

Next we will study some aspects of mathematical modeling to estimate acoustic damping algorithms.

For computer modeling, the structure of material must be formalized and all elements of this structure must be described. The one-dimensional and direct models of the materials are used in almost every theoretical 
description. We can found a suggestion; there distance between scatters is less than wavelength [11].

The dynamic characteristics of elementary layer in unipolar model case are the function of the approximate transfer $\hat{H}(s)$, the amplitude-frequency characteristic $\hat{H}(\omega)$, the phase-frequency characteristic $\hat{\varphi}(\omega)$ and the pulse characteristic $\hat{h}(t)$ :

$$
\begin{aligned}
& \hat{H}(s)=a \exp \frac{-s t_{s}}{1+b s}, \\
& \hat{H}(\omega)=\frac{a}{\sqrt{1+b^{2} \omega^{2}}}, \\
& \hat{\varphi}(\omega)=-a c t \operatorname{tg}(b \omega)-t_{s} \omega, \\
& \hat{h}(t)=\frac{a}{b} \exp -\frac{t-t_{s}}{b}[-(t-t)],
\end{aligned}
$$

Where: $a, b=$ const, $t_{s}=c d-$ waft delay time, $c-$ speed of ultrasound in material, $d-$ thickness of layer.

The calculations of coefficients $a$ and $b$ depends on the method of damping estimation and on criterion conviction of this estimation. There are three criteria that we can use to estimate the alteration of damping coefficient $\beta$ and link between coefficients a and $b$ [7].

The criteria of zero bias are used in spectral-shift and zero-crossing methods. This allows us to determine the coefficients $a$ and $b$ :

$$
\begin{aligned}
& a=e^{-\frac{\beta \omega_{0}}{(1-\beta \omega)^{0,5}}} \\
& \left.b=\frac{\beta}{\omega_{0}\left(1-\beta \omega_{0}\right)^{0,5}}\right]
\end{aligned}
$$

Obviously, this suggestion is useful only then value of $\beta$ does not exceed value $\frac{1}{\omega_{0}}$.

Simplicity and the speed of coefficients estimation are the main advantages of zero bias criteria.

All of these criteria mentioned above have their own methodical biases of damping estimation. It is stated that for large values of $\beta$ (1-1.5 Np/MHz - values are typical for composite materials) the reduced bias is $20-30 \%$.

The unipolar models do not appraise interference, scatter and reverberation. The problem with damping measurement can be solved only with base of definite three-dimensional modeling of wafting impulse and scatter dispersion [13].

Reflected from small capacity of the material signal can be expressed in this way:

$$
r(k)=g(k) * p(k)
$$

Where: symbol * means operation of torsion; $g(k)$ - incidentally spread reflectors reflecting white noise; $p(k)$ - signal reflected from area of material where spectrum must be calculated.

We can calculate:

$$
R(f)=G(f) P(f),
$$

Where: $G(f)$ - incident transfer characteristic of reflectors; $P(f)$ - spectrum of impulse.

From (21) we can make a conclusion that spectrum $R(f)$ is a multiplicatively awry copy of spectrum $P(f)$.

\section{Conclusions}

And finally we will give some objective limitations that have an influence on the estimation of acoustic damping:

1. Estimation of acoustic damping is performed according to incident distribution of scatters (then there is no definite information about reflex attribute in material).

2. Estimation of acoustic damping depends on the variation of reflection attributes in the material. Although it is already proven that acoustic damping depend more on ultrasound absorption than on distribution.

3. Frequentative dependence of acoustic damping is non-directional in some materials. That decreases the width of the spectrum of reflected impulses.

4. A priori correction of the effects of ultrasound radiation filtration effects is complicated.

5. The influence of defects in material to acoustic damping is unknown.

\section{References}

1. Artur R.M., Gurumurthy A. A single-pole model for the propagation of ultrasound in soft tissue. JASA. - Vol 77, No 4. - P. 1589-1597.

2. Classon I., Salomonson G. Estimation of varying ultrasonic attenuation // Ultrasound in Medical and Biology. -1995. - Vol 11, No 1. - P. 131-145.

3. Djordjevic B.B., Green R.E. Non-contact ultrasonic techniques for process control of composite fabrication // NDTnet - November 1997. - 1997. Vol. 2, No 11. - P. 125-133.

4. Kak A., Dines A. Signal processing of broadbandpulsed ultrasound: measurement of attenuation of soft biological tissues // IEEE Trans. on Biomedical Eng. - 1988. - Vol BME-25. - P. 321-343.

5. Kuc R. Estimating acoustic attenuation from reflected ultrasound signal: comparison of spectral-shift and spectral-difference approaches // IEEE Trans. Acoustic, Speech and Signal Process. - 1994. - Vol 32, No 1. - P. 1-6. 
6. Kuc R., Taylor R.J.W. Variation of acoustic attenuation coefficient slope estimates for in vivo liver // Ultrasound Medicine Biol. - 1992. - Vol 8, No 4. P. 403-412.

7. Leman S., Ferrari L., Jones J.P. et al. Perspectives attenuation estimation from pulse-echo signals // IEEE Trans. Sonic Ultrasound. - 1994. - Vol 31, No 4. - P. 352-360.

8. Narayana P.A., Ophir J. The measurement of attenuation in nonlinearly attenuation media by zerocrossing method // Ultrasound in Medical and Biology. - 1994. - Vol 10, No 6. - P. 715-718.

9. Pileckas E., Janavičius S. Echo-impulsinis slopinimo parametru nustatymas ultragarsinèje konstrukciju defektoskopijoje // Aviacija. - Vilnius: Technika, 1999. - Nr. 4. - P.100-102.

10. Research techniques in non-destructive testing / Edited by R. S. Sharpe. - Academic press London and New York, 1970. - 481 p.

11. Домаркас В.Й., Пилецкас Э.Л. Ультразвуковая эхоскопия. - Л.: Машиностроение , 1988. - 276 с.

12. Кайно Г. Акустические волны: Устройства визуализации и аналоговая обработка сигналов / Пер. с англ. - М.: Мир, 1990. - 656 с.

13. Кондратьев А.И. Прецизионные измерения скорости и затухания ультразвука в твёрдых телах // Акустическй журнал, 1990. - Т. 36, № 3. - С. 470-476. 